\title{
Bridging the Malnutrition Gap with Social Audits and Community Participation
}

\author{
Biraj Swain and Priti Dave Sen*
}

\begin{abstract}
There is an urgent need to increase coverage of the Integrated Child Development Scheme (ICDS) particularly in Madhya Pradesh and to overcome governance failures, such as staff absenteeism, leakage of funds and supplies and false reporting of coverage. By increasing community participation, ownership of the scheme, and improving programme oversight, social audits can result in increased coverage as well as better accountability among service-providers and the relevant line departments. The bulk of experience with social audits comes from implementation of the National Rural Employment Guarantee Act (NREGA), which mandates that social audits be conducted prior to fund release. There is also some experience of using social audits for ICDS in Andhra Pradesh and Orissa. This article examines the experiences from those two states and draws lessons for its application in states such as Madhya Pradesh.
\end{abstract}

\section{The context}

India's record on malnutrition is one of the poorest in the world. It is home to the highest number of underweight children, with almost half of all those under three years being underweight for their age. ${ }^{1}$ Malnutrition implies that the right amount and type of food, care and health do not get to the child during the period of rapid development, i.e. the window of opportunity period ( $0-2 / 3$ years of age).

Malnutrition during this period has serious debilitating impacts. The child will be prone to diseases and stunted brain and body growth. It is also an important cause of child mortality in this age group. The adverse consequences of low birth weight and malnutrition on health often extend well beyond childhood, into adult life. Low birth weight also plays a major role in the transmission of malnutrition from one generation to the next: malnourished mothers give birth to low-birth weight babies who carry the burden of malnutrition, unless rectified in the early stages.

The government of India has made considerable investments in improving the nutritional status of its citizens, through laws, policies and programmes and budgetary allocations. The central plank of this response is the nationally funded Integrated Child Development Scheme (ICDS). Targeting mothers and children aged 0-6 years, the main components of the scheme are pre-school education, supplementary feeding, immunisation and nutrition and health education. It focuses on improving the nutritional and health status of vulnerable groups such as children up to six years of age, adolescent girls, pregnant women and nursing mothers.

Initially available to the poorest of families in chosen blocks ${ }^{2}$ of India, the Supreme Court of India mandated universalisation of the scheme in 2001 in response to the case by the People's Union for Civil Liberties (now commonly known as the Right-to-Food case). ICDS IV, the next phase of the programme due to start shortly, aims to both expand the programme as well as deepen programme contents, especially, with respect to ensuring better targeting of nutrition-related inputs for children aged six months to three years, community ownership and participation. ${ }^{3}$

As with delivery of other public schemes and services, ICDS has been plagued with serious 
Box 1 National Rural Employment Guarantee Act (NREGA) social audit: pilot - process and results, Andhra Pradesh

- The pilot was rolled out with the Andhra Pradesh's (AP) Rural Development Department. Lack of government experience of public audits prior to the pilot was a major hurdle. Mazdoor Kissan Shakti Sangathan (a people's movement) and ActionAid - a civil society organisation, collaborated with the Government of AP to make the state officials exposed to the social audit experiences of Rajasthan and Orissa Food for Work schemes (the predecessor of NREGA).

- In AP, the pilot was on 12 civil works spread across three villages. The audits were primarily financial in nature and undertaken on completed works, i.e. closed files.

- The Audits found a staggering 90 per cent deviation between reported and actual works undertaken on the ground.

- Following this pilot, the GoAP decided to mainstream social audits in its NREGA programme. As of January 2009, the recovery from voluntary returns during social audits has been to the tune of Rs. 20 million. To put this in perspective, the revenue department's recovery from defaulters during the same period through legal action has been Rs. 10,000.

Ms Karuna Vakati Aakella, Director, Dept of Rural Development, Strategic Performance Incentive Unit.

implementation problems, many of which relate to weak management systems and oversights, such as poor planning and budgeting, nontransparent procurement and financial systems, and weak or no engagement of the community served. This, together with poor citizen knowledge of service entitlement, has resulted in serious governance failures, including staff absenteeism, leakage of funds and supplies (in this case mostly related to food procurement and distribution) and false reporting of coverage.

The recent spate of child malnutrition-related deaths in Khalwa ${ }^{4}$ block of Khandwa district, Majgawan ${ }^{5}$ and Unchehra ${ }^{6}$ blocks of Satna district and Sheopur district of Madhya Pradesh has aptly demonstrated the inadequacies of current approaches. The macro-picture of the central Indian state of Madhya Pradesh reinforces these concerns. The situation has worsened considerably from the second round of National Family Health Survey (NFHS), i.e. 1998-9 to the third round of NFHS, i.e. 2005-06. Remarkably, the percentage of underweight children has increased from 54 per cent to 60 per cent (NFHS-2 to NFHS-3).

Can community participation in the monitoring of ICDS make a difference? The potential seems certain. The World Bank (2006) notes:
'Malnutrition is usually invisible to malnourished families and communities. Families and governments do not recognise the human and economic costs of malnutrition ... The malnourished have little voice.' Drèze and Sen (1991) argue, it is 'essential to see the public not merely as "the patient" whose well-being commands attention, but also as "the agent" whose actions can transform society. Taking note of that dual role is central to understanding the challenge of public action against hunger.' One of the largest disconnects in ICDS governance is between what it promises and what it delivers. Hence, there would seem to be great potential for public participation, in terms of understanding, monitoring and working in a proactive manner for better programming.

There have been some forms of public action that have been showing results in public funded programmes. These include Parents'

Committees for Monitoring of Schools in Gujarat and Uttar Pradesh, Report cards on water sanitation services in urban slum areas of Bangalore and Mumbai, adolescent girls' committees for monitoring of water sanitation in Orissa and Jharkhand, and community planning and monitoring committees at primary health centres in Chhindwara and Sidhi districts of Madhya Pradesh. 
Social audits represent one such form of public action which is gaining currency because of the scale and depth of community participation it seems to generate. The bulk of this experience comes from implementation of the National Rural Employment Generation Scheme (NREGA), ${ }^{7}$ which mandates that social audits be conducted by beneficiary communities and pro forma ratification occurs before fund release (Aakella and Kidambi 2007). Box 1 summarises the NREGA experience with social audits in Andhra Pradesh, suggesting that they highlighted problems and improved process outcomes.

ICDS also plans to experiment with social audits. The ICDS IV Project Concept Note, outlining details for the next phase stipulates the importance of the use of social audits, together with other community participatory approaches.

\section{What is a social audit?}

A social audit is a process in which the people work with the government to monitor and evaluate the planning and implementation of a scheme or programme. The social audit process is critically dependent on the demystification and wide dissemination of all relevant information.

The NREGA empowers people to play an active role in the implementation of a programme through Gram Sabhas, social audits, participatory planning and setting up of local Vigilance and Monitoring Committees. Active community participation is particularly important for ensuring transparency and public accountability. Thus, there is a role for all grassroots institutions such as mothers' committees, local beneficiary committees, selfhelp groups and user groups in spreading awareness, mobilising parents/villagers and in monitoring the implementation of the scheme.

It goes without saying that institutionalising social audits necessarily requires a partnership between civil society and the state (Burra 2007). Can civil society have a synergistic and non-adversarial relationship with the state while also drawing attention to corruption and nepotism within the state machinery? This is the tricky part. Both civil society organisations (CSOs) and the state have to be ready to trust each other and appreciate each other's strengths and weaknesses.

In Andhra Pradesh (AP), the context is promising - state and district resource persons are recruited from the ranks of CSOs and user groups with a track record of experience with social mobilisation and community empowerment. In addition AP has decided that non-government organisations will not be subcontracted to undertake social audits by themselves - it is a joint government-civil society partnership.

\section{ICDS Social Audit Pilots in Andhra Pradesh and Orissa \\ 3.1 The Andhra Pradesh Initiative}

Ananthpur district is one of the most backward districts of Andhra Pradesh. The National Rural Employment Guarantee Act (NREGA) was launched here in 2005 by the Prime Minister and the social audit of NREGA began in August 2006. Thanks to the NREGA social audits, the concept of public scrutiny of government programmes is acceptable to district level government officials and there is a battery of barefoot auditors at the district and block levels.

The ICDS Social Audit pilot in Ananthpur district is a more recent initiative, and comprises a tripartite agreement between the Department of Women and Community Development (DWCD), Government of Andhra Pradesh, Centre for Social Development (CSD), a Delhibased non-government organisation working on governance and service delivery of social security programmes and Centre for Environment Concerns, a Hyderabad based State resource agency working on rural livelihoods and NREGA. The implementing partners at the district level are agencies with good grass-roots presence and prior experience of audit. This partnership is meant to build capacity and audit 300 Anganwadi centres (AWCs).

At the district level, the process started with the commitment of the highest order officials i.e. District Magistrate, District Programme Officer heading the DWCD at district level and the Chief Medical Health Officer. That this initiative has the sanction of the Principal Secretary ${ }^{8}$ of DWCD of the Government of Andhra Pradesh made progress smoother. The non-negotiable steps, as shared by the departmental officials and the auditors are:

- Consensus building among front-line and field level staff (anganwadi workers) and Supervisors regarding the need for social 


\section{Box 2 Programme deficiencies}

\section{In Orissa}

- Supplementary nutrition not reaching those in real need and those who were reached were not receiving adequate quantities of food

- Irregular delivery of immunisation services for children and pregnant mothers

- Lack of timely identification and referral of malnourished children

- Health and nutrition education sessions held very infrequently

- Several emergency feeding centres providing dry rations in place of cooked food

- Stock registers were not maintained in many Centres

- Process of appointing anganwadi workers was not transparent (e.g. post was not advertised, no specifications were provided on required qualifications, request for payment prior to appointment, etc.)

- Absence of food committees and lack of community awareness regarding the mandate of such committees in monitoring ICDS services and functioning

- Over-reporting of child attendance at Gentres.

\section{In Andhra Pradesh}

- Panchayat and people's participation had been minimal in ICDS

- Anganwadi Centre buildings and sanitation facilities were mostly inadequate

- Community perceived Early Child Education materials to be inadequate

- 20-30 per cent of anganwadi workers did not reside in the village

- Frequent stockout of supplementary nutrition, sometimes for up to 20 days

- The anganwadis were perceived as supplementary feeding centres only and there was scant idea about the complete range of services provided

- Mostly the AWCs were located in sites which were not habitation-proximity based, but political-patronage based

- AWCs' infrastructure availability was an issue itself, with more than 30 per cent of AWGs without their own building.

audit by highlighting issues around public discussion on system blockages, higher order challenges, political interference

- Perception by DWCD that ICDS Social Audit represents effective Information Education Communication (IEG) for communicating the range of services and entitlements under the ICDS programme beyond supplementary nutrition

- Realistic timeline: In the case of Ananthpur, eight months is allocated to covering 300 AWCs (population of 300,000) under the audit 
(inclusive of preparatory phase and the real audit, the public sharing through gram sabha and follow-up of the findings)

- Intensive capacity building of the cadre, to leave something in the district beyond the intervention period

- Clear assurance from the district heads about no retributive action against front-line staff in the field if service inadequacies are exposed

The Audit was carried out by a multi-stakeholder team comprising of a Team Leader from CSO; a Co-lead: an ICDS Supervisor (from another block); one member from an NGO/Community based organisation; two members from the District Water Management Association (rural development department); one or two local citizens/elders and opinion-shapers; and one member from the health department, such as an Accredited Social Health Activist (ASHA). ${ }^{9}$

The audit process comprises record perusal and physical verification, and looked into:

- All the 17 registers at the AWC; the issues emerging from them and how these were being maintained

- Child health issues identified at AWG crossverified with community

- Mothers' health issues identified at AWC cross-verified with the mothers

- Sanitation of the AWC

- Immunisation

- Home visits by the anganwadi worker

- Early child education material and how that was being imparted for improved learning skills among the children.

Social audits will necessarily bring out issues of systemic failure and leakages. When the poor testify, they also become extremely vulnerable to threats from ruling elites and the state machinery. How will those who testify in these public hearings be protected against intimidation? Since the majority of the poor are not organised, who will protect their rights? Clearly, the state has a major role to ensure the safety and security of its citizens and this has to be done in partnership with civil society organisations. When social audits are done by civil society organisations (CSOs) taking a lead and the state taking a back seat, the chances of a backlash against the poor after the social audit is over are much greater unless the state takes responsibility to protect them.

\subsection{The Orissa initiative}

The approach adopted in Bolangir District of Orissa for the ICDS social audit is quite different from that just described in Andhra Pradesh. Here, a CSO, Anchalik Vikas Samiti, led the process without the cooperation of either the Gram Sabha (local elected body) or the district government officials. Permission to hold a Gram Sabha meeting to initiate the social audit was requested, however both the village and district elected representatives refused. The CSO then sought an alternative path by encouraging the members of the peoples' organisation who are part of the Gram Sabha to convene a special Gram Sabha meeting through a memorandum, as is permitted under the Gram Panchayat rules. At this special meeting, it was decided a Social Audit Forum be established, and the Right to Information (RTI) Act ${ }^{10}$ used to gain information on the functioning of the ICDS programme.

As a result of the application under RTI, the Forum was given access to several registers, enabling them to assess volume and quality of services provided by the Anganwadi Centre, as well as systems and management arrangements. For example, with respect to the latter, they were able to probe into: how anganwadi workers were selected; how the location of the Centre was decided; and process for issuance of contracts related to food and other supplies.

The effort succeeded in unearthing many programme deficiencies (see Box 2), however, without the participation of the public officials, it remains unclear how this process has actually led to improvements in the functioning of the programme. Presumably, such an approach does increase awareness of service entitlements and thus increases service uptake, and can also lead to citizen pressure for service improvements. However, the risk of this approach is of a more confrontational response.

\section{ICDS deficiencies identified in Orissa and Andhra Pradesh}

Both social audits conducted in AP and Orissa succeeded in throwing light on programme and governance failures (Box 2). 
- Audit processes per principle should never be government led to maintain credibility and hence there needs to be a mature civil society organisation which can effectively work collaboratively on monitoring with the State.

- Government/Department's most important role is to provide information and only institutional ownership of the process at the highest level can make this possible.

- All the actors, i.e. government, NGOs, should also have a partnership of funding to maintain the independence of findings, hence the NGOs facilitating this work need to create some fund of their own to maintain the authenticity of the findings.

- Andhra Pradesh has had a consistent donor investment from the reforms programme, a lot of which has been directed at governance reforms and as part of the DFID support; 12 departments have SPIU (Strategic Performance Incentive Units) which have been unblocking some of the challenges and catalysing public participation. Although similar SPIUs need not be existent in departments in states wanting to introduce social audit pro forma yet, some strategic unit/champions with the highest level of ownership from state and departments are necessary for driving the cause.

- Civil society organisations with technical knowledge and the commitment to demystify sectors and transparency for increased public participation are key to the agenda.

- It is important that senior officials attend the public hearings at the culmination of the audit process and it is important that some redressal happens, and happens fast and visibly, for the faith and cooperation of the community to be retained.

\section{Impacts of the social audit: some early findings from Andhra Pradesh}

The following service uptake and delivery improvements can be directly attributable to social audit: ${ }^{11}$

- Earlier, stockout period of supplementary nutrition was on average 20 days; however it has been almost non-existent since the audits were undertaken.

- ASHA has replaced AWW as the first port of call for pregnant women. This has improved the identification and referral of pregnant women to Anganwadi Centres.

- The Department responded to the community's preference for modified therapeutic food provided by AP Agro.

- In response to lack of buildings for an Anganwadi Centre, the Health Department responded by negotiating for resources from the National Bank for Rural Development and the Backward Region Grant Fund.

- Cross-departmental meetings with supervisory staff have been institutionalised, resulting in better convergence around issues common to both health and WCD departments

- Post the social audit, the AWCis are coming to be known for the comprehensive package of ICDS services rather than just Atta (wheat flour) Schools. Their role beyond just supplementary nutrition distribution has been known and recognised.

- The uptake of services has increased with more children being registered post-audits and more awareness regarding growth monitoring of children. In Ananthpur prima facie there is evidence that there has been a 15-20 per cent increase in the enrolment of children and community interest in the frequency of weighing at the centre, and efficiency of this has increased considerably.

While the service-uptake and community ownership and participation in ICDS has increased considerably, its impact on nutrition could not be inferred conclusively. For an initiative which is less than eight months old, it is early days to comment on the outcome of this 
intensive process on the nutritional status of children, but if the ICDS theory of change is correct, better programme implementation should lead to better nutritional outcomes of beneficiaries. Box 3 summarises the lessons learned for making social audits successful and scalable.

While conceptually there aren't many differences between NREGA and ICDS social audits, the latter are likely to be more challenging. Mobilising communities around a financial audit is much easier than through complex and entitlement-based services like ICDS, and hence getting the citizens to be interested and motivated will require a lot more investment and acumen. On the other hand, ICDS social audits will raise the profile and priority given to nutrition whereas NREGA is already a priority.

\section{Is Madhya Pradesh ready for social audits?}

Some of the non-negotiables are already existent in Madhya Pradesh, i.e. prioritisation of nutrition on the agenda. The recent spate of malnutrition deaths has resulted in nutrition reportage being catapulted to front-pages and the nature of coverage has been mature, increasing the standard of the debate. ${ }^{12}$ The senior officials of the nodal department, i.e. DWCD have been discussing the idea for the same reason as in AP, i.e. social audit as an entry point to a child wellbeing campaign. However, there are some crucial factors missing:

- Even the rural employment guarantee act (which mandates audits) has not had audits in the state, hence the state officials are not used to the concept of being publicly audited for the works/schemes they implement.

- The state has very limited civil society organisations with the maturity to work collaboratively with the state on monitoring.

- The culture of public debate is not yet mainstreamed.

- The commitment required to make long-term investment in building capacity at grassroot level to audit public programmes is still some way off.
Perhaps with a catalytic organisation like the Centre for Environment Concerns/Mazdoor Kissan Shakti Sangathan, citizens' engagement might be a reality. A timeline of more than three years is required to realistically cover the entire state's high alert challenging malnutrition endemic blocks.

\section{Conclusion}

Improving the nutrition status of infants requires behaviour change at many levels. While the importance of partnerships between communities and local governments for social audits cannot be emphasised enough, the programmes themselves have to be technically sound.

There is no uncomplicated way of introducing social audits without the willingness of leadership. Considering the fact that social audits reflect shifts in the balance of power, their implementation requires a very high degree of political willingness and bureaucratic persistence.

We still do not know if social audits improve nutrition status, but we can reasonably infer improvements from measurable improvements in delivery and uptake. And social audits do show promise in improving uptake and delivery in states that are ready for them such as AP. In states like Orissa, where the government-civil society partnership is not yet strong enough, they will likely deliver fewer improvements although they can still highlight the problems with ICDS. In states such as MP which are discussing social audits, it is important to be cognisant of the preconditions that have to exist to make success likely and the patience that it requires to put these in place.

ICDS IV has committed to mark a shift from inputs-based programme management information system (MIS) to behaviour change outcomes. That commitment, combined with a greater number of AWCs experimenting with social audits should allow us to estimate whether social audits do in fact accelerate undernutrition reductions. Given the right conditions, the prospects seem good. 


\section{Notes}

* This article draws on field visits made by the authors to Andhra Pradesh and Madhya Pradesh, and on secondary sources for the Orissa experience. Extensive field visits in the ICDS Social Audit pilot district, i.e. Ananthpur in January 2009. The authors are extremely grateful to Mr Jagannath Rao, state resources for NREGA and ICDS, Mr KS Gopal, Ms Bhanuja and Dr Thimma Reddy of Centre for Environment Concerns for sharing their work, challenges and their insights. The authors also acknowledge the insights shared by Ms Karuna Vakati Aakella, Director, Strategic Performance Incentive Unit, Department of Rural Development, Government of AP and Mr Satyajit Rao Vagvala, Knowledge Manager, Social Development, and his team from Centre for Good Governance 'on the institutional arrangements in Andhra Pradesh which makes state and non-state collaboration for social audits possible'.

1 According to UNICEF, 47 per cent of children in India are underweight, which is worse than sub-Saharan Africa. Along with Pakistan and Bangladesh, India is home to more than half of the world's malnourished children.

2 Lowest administrative unit in India.

3 ICDS IV Project Concept Note, Central Project Management Unit, Ministry of Women and Child Development, Government of India, 2007.

455 in the period between June to early September, 2008.

546 reported deaths in the same time period as above.

\section{References}

Aakella, Karuna Vakati; Kidambi, Souwmya (2007) 'Challenging Corruption with Social Audits', Economic and Political Weekly 42.5: 3-9 February

Burra, Neera (2007) Transparency and Accountability in Employment Programmes: The Case of NREGA in Andhra Pradesh. Annandale-on-Hudson NY: The Levy Economics Institute of Bard College
614 reported deaths in the same time period as above.

7 Enacted in 2005, National Rural Employment Guarantee Act has a national remit and guarantees 100 days' wage employment per household. It is based on self-targeting.

8 Highest official of any department at the state level.

9 The crucial addition of National Rural Health Mission, this activist is supposed to be the core link of communitisation, spreading health awareness and helping people access health services.

10 Right to Information Act (Government of India 2005) was enacted to enable citizens to secure access to information under the control of public authorities, in order to promote transparency and accountability in the working of public authorities.

11 As shared by the Child Development Programme Officer, Mrs Shyamalamma for the Kuderu Mandal and the District Programme Officer, Ms Muthialamma (i.e. the programme managers at sub-district and district levels, respectively) and the citizens the authors interacted with from Kadiri and Kuderu mandals during their field visit to Ananthpur in January 2009.

12 The Right to Food coalition (a group of civil society academics) was keen that with the timing of the state elections, the issue should not be cynically politicised and hence, the media along with the civil society actors, were keen that the focus remains on the issue of malnutrition and its larger determinants.

Sen, Amartya; Drèze, Jean (1991) Hunger and Public Action, Oxford: Oxford University Press World Bank (2006) Repositioning Nutrition as Central to Development: A Strategy for Large-scale Action, Washington DC: World Bank 